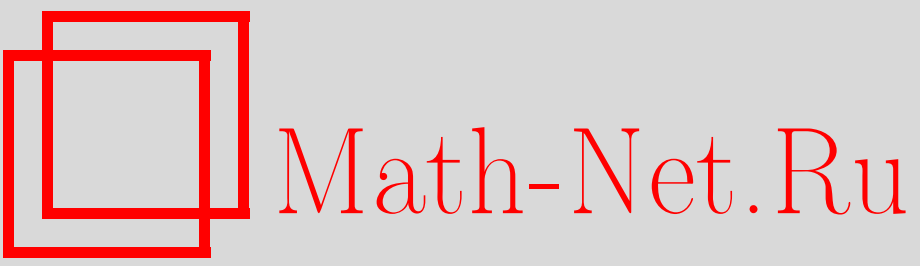

В. В. Абрамов, Электронный каталог орбитальной эволюции малых тел Солнечной системы: разработка информационной базы и интернет-ресурса, Becmн. Сам. гос. техн. ун-та. Сер. Физ.-мат. науки, 2008, выпуск 2(), 275-278

DOI: https://doi.org/10.14498/vsgtu633

Использование Общероссийского математического портала Math-Net.Ru подразумевает, что вы прочитали и согласны с пользовательским соглашением http://www. mathnet.ru/rus/agreement

Параметры загрузки:

IP : 54.166 .219 .16

26 апреля 2023 г., $14: 55: 23$ 
Информатика

УДК 52-13(083.8):523.44

\section{ЭЛЕКТРОННЫЙ КАТАЛОГ ОРБИТАЛЬНОЙ ЭВОЛЮЦИИ МАЛЫХ ТЕЛ СОЛНЕЧНОЙ СИСТЕМЫ: РАЗРАБОТКА ИНФОРМАЦИОННОЙ БАЗЫ И ИНТЕРНЕТ-РЕСУРСА}

\section{В.В. Абрамов}

Самарский государственный технический университет, 443100, Самара, ул. Молодогвардейская, 244.

E-mail: vva85@mail.ru

Изложены основные этапы разработки электронного каталога орбитальной эволючии малых тел Солнечной системы. Дано краткое описание внутреннего устройства интернет-ресурса, его структуры и интерфейса. Описаны основные принципы работы с сайтом.

Ключевые слова: каталог, астероиды, кометы, орбиты, эволюиия, малье тела, Солнечная система, информационная база, интернет-ресурс, разработка.

Каталогизация малых тел Солнечной системы является важным этапом в решении проблемы «астероидной опасности». Каталоги астероидов и комет содержат ценную информацию о распределении этих тел в Солнечной системе и об эволюции элементов орбит с течением времени. Данные сведения позволяют предсказать столкновение малого тела с Землёй и принять соответствующие меры для предотвращения катастрофы.

При создании в 2007 году каталога орбитальной эволюции астероидов [1] были использованы данные о 3823 астероидах групп Аполлона, Амура, Атона и выявлен 291 объект, сближающийся с Землёй на расстояние менее 0,01 астрономической единицы на интервале времени с 1800 по 2204 годы. Созданный в том же году каталог орбитальной эволюции короткопериодических комет [2] содержит сведения о 190 объектах.

В настоящее время ежегодно открываются сотни новых астероидов групп Аполлона, Амура, Атона и несколько короткопериодических комет. Некоторые из вновь открытых объектов могут иметь сближения с большими планетами Солнечной системы, в том числе с Землёй. Данные об уже открытых объектах постоянно уточняются.

В связи с этим непрерывно обновляется и банк данных, использованный при создании каталогов $[1,2]$ и описанный в этих работах. На основе начальных данных элементов орбит малых тел, получаемых из базы данных DASTCOM [3] (Database of ASTeroids and COMets) американской Лаборатории реактивного движения (JPL), осуществляется вычисление эволюции орбит вновь открытых объектов, а также производится перерасчет для объектов, начальные данные которых были уточнены. Для этого используется программное обеспечение, описанное в работе [4].

В основе алгоритма расчета эволюции орбиты лежит математическая модель, описывающая движение малого тела с помощью дифференциальных уравнений с учётом гравитационных и релятивистских эффектов в барицентрической системе координат [5]. Решение системы дифференциальных уравнений осуществляется с по-

Абрамов Владимир Владимирович - аспирант кафедры прикладной математики и информатики Самарского государственного технического университета. 
мощью модифицированного метода Эверхарта 27 порядка с переменным шагом интегрирования.

Вышеупомянутый банк данных орбитальной эволюции астероидов групп Аполлона, Амура, Атона и короткопериодических комет физически представляет собой базу данных, реализованную в СУБД MySQL. База данных содержит сведения о начальных данных объектов, эволюции их орбит и сближениях этих объектов с большими планетами Солнечной системы и Луной.

В настоящее время данная информационная база доступна всем желающим для просмотра благодаря созданному веб-интерфейсу базы данных, которая размещенна в виде интернет-ресурса на сайте SmallBodies. Ru ${ }^{1}$

Данный сайт представляет собой электронную версию каталога орбитальной эволюции малых тел Солнечной системы. В настоящее время он содержит информацию о 5479 астероидах групп Аполлона, Амура, Атона и 197 короткопериодических кометах.

Сайт написан на языке веб-программирования РНР 5 и является динамическим. Это дает пользователю ряд удобных функциональных возможностей для получения информации о малых телах Солнечной системы в требуемом ему наглядном виде. При навигации пользователя по сайту и просмотре той или иной информации осуществляются запросы к базе данных MySQL посредством языка PHP. Полученные данные обрабатываются и представляются в виде html-страницы, содержащей графики или таблицы, отсортированные в нужном пользователю виде.

Отображение графической информации осуществляется посредством Java-aпплетов, внедрённых в веб-страницу, и передачи в них параметров с помощью РНР.

Работа с сайтом SmallBodies.Ru сводится к просмотру общих статистических данных о малых телах или выбору интересующего объекта и просмотре подробной информации о нем. Структуры разделов, содержащих каталог астероидов и каталог комет, идентичны. Поэтому рассмотрим принцип навигации по сайту на примере каталога астероидов.

Выбрать астероид для просмотра возможно тремя разными способами. Во-первых, есть возможность осуществить текстовый поиск ${ }^{2}$ объекта. При этом все астероиды, в названии, номере или обозначении которых встречается строка поиска, будут отображены в виде табличного списка. Второй способ состоит в использовании страницы отбора астероидов по критерию ${ }^{3}$, на которой отображаются все астероиды, удовлетворяющие заданным критериям. И, наконец, интересующий объект можно выбрать на странице тесных сближений ${ }^{4}$. Во всех трех случаях элементы списков представлены в виде ссылок, по которым можно перейти к просмотру подробной информации об астероиде.

После выбора интересующего объекта можно посмотреть различную информацию о нем. На странице общих сведений ${ }^{5}$ отображаются такие данные, как количество наблюдений объекта, его приблизительный размер и т. д. Страница начальных данных $^{6}$ содержит точные значения элементов орбиты выбранного астероида на некоторые моменты времени. Эти данные использовались при расчете эволюции его орбиты. На странице сближений ${ }^{7}$ отображаются наиболее тесные сближения астероида с другими небесными телами. В таблице указываются расстояния между центрами тел в моменты максимальных сближений.

Эволюцию орбиты с шагом 100 дней в табличном виде на интервале времени

\footnotetext{
${ }^{1}$ http://smallbodies.ru/

${ }^{2}$ http://smallbodies.ru/asteroids/search/

${ }^{3}$ http://smallbodies.ru/asteroids/summary/filter/

${ }^{4}$ http://smallbodies.ru/asteroids/summary/closest/

${ }^{5}$ http://smallbodies.ru/asteroids/info/general/

${ }^{6}$ http://smallbodies.ru/asteroids/info/initial/

${ }^{7}$ http://smallbodies.ru/asteroids/info/approaches/
} 
с 1800 по 2206 гг. можно посмотреть на соответствующей странице ${ }^{8}$. По умолчанию отображаются данные, вычисленные относительно последних начальных данных. Но имеется возможность просмотра эволюции орбиты, соответствующей и более ранним начальным данным. Для этого нужно выбрать интересующую дату начальных данных в раскрывающемся списке.

Более наглядным является представление эволюции орбиты в виде графиков 9 . По умолчанию отображается график изменения большой полуоси $a$. Чтобы посмотреть графики изменения других элементов орбит, достаточно перейти по одной из ссылок, расположенных над графиком. Для просмотра графиков должна быть установлена виртуальная машина Java ${ }^{10}$.

Эволюцию орбиты интересующего астероида также можно посмотреть в режиме трехмерного просмотра ${ }^{11}$. На этой странице можно оценить положение орбиты астероида в пространстве относительно орбит больших планет Солнечной системы. Имеется возможность изменять угол обзора, степень увеличения и положение точки обзора с помощью мыши. Для просмотра эволюции орбиты в трехмерном режиме помимо виртуальной машины Java должно быть установлено расширение Java 3D ${ }^{12}$.

Сайт является многоязычным. Для смены текущего языка достаточно нажать соответствующую ссылку в правой нижней части страницы. При этом произойдет ее перезагрузка, и в дальнейшем вся информация на сайте будет представлена на выбранном языке.

Большинство информации на сайте отображается в виде таблиц с постраничным выводом. Ссылки для переключения между страницами располагаются под таблицей. Для каждой таблицы имеется возможность сортировки по различным столбцам (по возрастанию и убыванию).

Для описания орбиты и положения объекта на ней используются следующие обозначения:

$$
\begin{aligned}
& M-\text { средняя аномалия в градусах (положение тела на орбите); } \\
& a-\text { большая полуось орбиты в астрономических единицах; } \\
& e-\text { эксцентриситет орбиты; } \\
& \omega-\text { аргумент перигелия орбиты в градусах; } \\
& \Omega \text { - долгота восходящего узла орбиты в градусах; } \\
& i \text { - наклон орбиты к плоскости эклиптики в градусах; } \\
& q-\text { перигелийное расстояние в астрономических единицах; } \\
& P \text { - период обращения по орбите (в средних солнечных сутках для астероидов } \\
& \text { и в годах для комет); } \\
& T \text { - момент прохождения перигелия (для комет); } \\
& L-\text { - элиптическая долгота в градусах (для комет); } \\
& B \text { - эклиптическая широта в градусах (для комет). }
\end{aligned}
$$

В таблицах сближений астероидов с большими планетами и Луной приведены все сближения на расстояние менее 0,01 а.е. Для комет данное ограничение составляет 0,1 а.е. с планетами земной группы и 0,5 а. е. - с остальными. В данных таблицах на интервале времени с 1800 по 2206 гг. указываются моменты сближений по всемирному времени и расстояния в астрономических единицах и километрах.

\footnotetext{
${ }^{8}$ http://smallbodies.ru/asteroids/info/evolution/tables/

${ }^{10} \mathrm{http}$ ://www. java.com/download/

11 http://smallbodies.ru/asteroids/info/evolution/3dview/

12 https://java3d.dev.java.net/binary-builds.html
} 
Таким образом, электронный каталог SmallBodies. Ru предоставляет данные об орбитальной эволюции астероидов групп Аполлона, Амура, Атона и короткопериодических кометах, а также о сближениях этих объектов с большими планетами Солнечной системы, в том числе с Землёй. Данная информация может помочь при изучении движения потенциально опасных объектов и позволяет оценить риск их возможного столкновения с нашей планетой в будущем для принятия своевременных мер по предотвращению катастрофических последствий.

Работа выполнена при поддержке Федералъного агентства по образованию (проект РНП. 2.1.1.1689)

\section{БИБЛИОГРАФИЧЕСКИЙ СПИСОК}

1. Заусаев, А.Ф. Каталог орбитальной эволюции астероидов, сближающихся с Землёй с 1800 по 2204 гг. [Текст] / А.Ф. Заусаев, В. В. Абрамов, С.С. Денисов.-М.: Машиностроение-1, 2007. - 608 с. ISBN 978-5-94275-373-3.

2. Заусаев, А. Ф. Каталог орбитальной эволюции короткопериодических комет с 1800 по 2204 гг. [Текст] / А. Ф. Заусаев, А. А. Заусаев. - М.: Машиностроение-1, 2007. - 410 с. ISBN 978-5-94275-372-6.

3. The Asteroid Orbital Elements Database [Electronic Resource]. - Access Regime: ftp://ftp. lowell.edu/pub/elgb/astorb.html

4. Денисов, C. С. Разработка программного обеспечения с целью создания банка данных астероидов [Текст] / С. С. Денисов / Матем. моделирование и краевые задачи: Тр. пятой Всерос. научн. конф. с междунар. участием. Ч. 3. - Самара: СамГТУ, 2008. C. 90-92. - ISBN 978-5-7964-1089-9.

5. Newhall, X.X. DE 102: a numerically integrated ephemeris of the Moon and planets spanning forty-four centuries [Text] / X. X. Newhall, E. M. Standish, Jr. and J. G. Williams // Astron. \& Astrophys. - 1983. - No. 125. - P. 150-167.

Поступила в редакцию 23/IX/2008;

в окончательном варианте - 09/X/2008.

\section{MSC: 85-04}

\section{ELECTRONIC CATALOGUE OF ORBITAL EVOLUTION OF SMALL BODIES OF THE SOLAR SYSTEM: DATABASE AND WEB-SITE DEVELOPMENT}

\section{V. Abramov}

Samara State Technical University,

443100, Samara, Molodogvardeyskaya str., 244.

E-mail: vva85@mail.ru

The main stages of development of the electronic catalogue of orbital evolution of small bodies of the Solar system are introduced. The short description of the web site architecture, its structure and interface has been given. Guidelines for web-site users are described.

Key words: catalogue, asteroids, comets, orbits, evolution, small bodies, Solar system, database, web site, development.

Original article submitted 23/IX/2008; revision submitted $09 / \mathrm{X} / 2008$.

Abramov Vladimir Vladimirovich, Postgraduate Student, Dept. of Applied Mathematics and Computer Science of Samara State Technical University. 